\title{
Self-Medication Practice in Limmu Genet, Jimma Zone, Southwest Ethiopia: Does Community Based Health Insurance Scheme Have an Influence?
}

\author{
Bayu Begashaw Bekele $\mathbb{D}^{\mathbb{1},{ }^{1,2}}$ Shibiru Tesema Berkesa, ${ }^{3}$ Enyew Tefera, ${ }^{3}$ and Abera Kumalo ${ }^{4}$ \\ ${ }^{1}$ Department of Public Health, College of Health Sciences, Mizan Tepi University, Mizan Aman, Ethiopia \\ ${ }^{2}$ Institute of Public Health, College of Medicine and Health Sciences, University of Gondar, Gondar, Ethiopia \\ ${ }^{3}$ Department of Pharmacy, Jimma University, Jimma, Ethiopia \\ ${ }^{4}$ Medical Laboratory Sciences Department, College of Medicine and Health Sciences, Wolaita Sodo University, Sodo, Ethiopia \\ Correspondence should be addressed to Bayu Begashaw Bekele; baybeg121@gmail.com
}

Received 28 August 2017; Revised 4 December 2017; Accepted 11 January 2018; Published 20 February 2018

Academic Editor: Amnon Sintov

Copyright (c) 2018 Bayu Begashaw Bekele et al. This is an open access article distributed under the Creative Commons Attribution License, which permits unrestricted use, distribution, and reproduction in any medium, provided the original work is properly cited.

\begin{abstract}
Background. Self-medication, which is a form of self-care, is an important initial response to illness, and many illnesses can be successfully treated at this stage. It is practiced by a considerable proportion of the population and is affected by sociodemographic and economic factors. This study was conducted to assess the practice of self-medication and associated factors in Limmu Genet's town households, Jimma Zone, Southwest Ethiopia. Methods and Materials. A community based cross-sectional study was done. Systematic sampling technique was used to select participants. Data was collected by face-to-face interviews by using structured questionnaires. After checking the completeness, missing values, and coding of questionnaires, data was tabulated and calculated on SPSS version 20.0. Finally data was presented in tables, graphs frequency, percentage, and cross-tabulation with different variables. Result. In this study, both self-medication and the prevalence of diseases among households were $78.1 \%$. That constituted any kind of illness reported by participants. Conclusion. Self-medication practice is common among community members regardless of being community based health insurance members. Therefore, it needs pertinent health education on legal prescriptions and use of medicines as well as strengthening the access of community based insurance.
\end{abstract}

\section{Introduction}

1.1. Background. Providing useful and effective healthcare to the community is essential to keep good health as well as a vital agenda of life. In low- and middle-income countries (LMICs), rural inhabitants especially have poor access to modern healthcare infrastructures and low affordability of drugs and medical supplies [1]. Therefore, most people acquire diseases easily. Consequently, episodes of illness are haphazardly treated by self-medication. But the means of selftreatment vary from person to person depending on several factors. The main care of illness is self-care, the oldest and most abundantly used behavior that affects the health of individuals either negatively or positively $[1,2]$.

Thus, self-medication can be defined as the use of drugs to manage self-diagnosed health complaints or symptoms or the usual use of a prescribed drug for chronic or acute diseases or disease manifestations. According to some studies, the demand of patients is increasing for efficient drugs available without prescription [3, 4]. However, inappropriate selfmedication leads to resources wastage, increases microbial resistance, and could generally result in serious health hazards such as adverse drug reaction and persistent suffering [5].

Medicines for self-medication are often called "nonprescription" or "over-the-counter" (OTC) medicines, which are claimed as safe, effective for use, and available without a medical professional's prescription. In some countries, OTC products are available and dispensed by supermarkets and other outlets. On the other hand, medicines that require a doctor's prescription are called prescription products [6]. 
Self-medication is a form of self-care, which is basically performed to treat illnesses, with the ability to relieve illnesses at this stage. Self-medication is used by a significant number (proportion) of the population. It is affected by socioeconomic and demographic health facilities and economic factors. Although some healthcare providers exhibit negative understanding and perspectives towards self-medication, the World Health Organization (WHO) recognizes the existence of a valid role of it. There are a number of reasons why self-medication gets focus. The transition of the trend of diseases especially chronic ones with attendant shift from cure to care is becoming a large-scale transition. In addition, the inaccessibility (failures) of the healthcare system with its uneven distribution of drugs, unaffordable price, and the issue of curative stance of drugs is notable [7, 8]. Also, patient-related factors anticipate inappropriate antimicrobial use and contributed to the increasing prevalence of antimicrobial resistance (AMR). For instance, self-medication with antimicrobials by patients contributes to the problem of AMR [9]. Moreover, it might be associated with some risks such as drug interactions, adverse drug reactions, increased polypharmacy, incorrect diagnosis, and drug dependence [3, $10,11]$.

Community based health insurance $(\mathrm{CBHI})$ is defined as a mechanism that households in a community (the population in a village, a district, or other geographical areas, or a socioeconomic or ethnic population group) use to finance or cofinance the current and/or capital costs associated with a given set of health services and enable them to have some involvement in the management of the community financing scheme and organization of health services [12]. It aims to improve access to healthcare and to protect households from pocket-payment related risks. It incorporates a wide range of nonprofit schemes providing risk pooling to cover a part of or all healthcare related costs. To their minimum or maximum level, CBHI schemes target households that generate their income from the informal economy and are excluded from legal and formal social protection. Also, having a membership is therefore usually voluntary. Basically, the schemes encourage active decisionmaking and management. Consequently, building on mutual aid and unity, risk sharing is as inclusive as possible and membership premiums are independent of the individual health status. Nevertheless, payments are usually flat rates and, thus, are not adjusted and are requested according to the financial capacity of individuals $[13,14]$. Therefore, being a $\mathrm{CBHI}$ scheme member might be one of the elements for selfmedication prevalence in the study area.

Moreover, limited access to health information and education on medications and diseases might be linked with hazardous drawbacks to communities in rural areas. Lack of trained pharmacists/professionals creates favorable environment for self-medication. Even though SMA is somehow important to treat minor ailments, wrong self-medication practice may cause serious adverse drug reactions and possible fatal consequences. For instance, currently, AMR is becoming globally prevalent, mainly in LMICs [15]. For this reason, the transmission of new forms of resistant pathogens could be fast and can easily spread intercontinentally. World health leaders have described AMR as "nightmare bacteria" that "pose a catastrophic threat" to people in every country in the globe [16]. Therefore, the issues of drug availability, preference, and proper use are a vital issue to the global community [17].

However, illegal scandalmongers of drugs are prevalent in several LMICs. Thus, the use of these drugs from informal sources increases the chances of self-medication and home drug storage. The availability of drugs at home has enabled an extent of self-medication for illnesses. For that reason, handling unnecessary dangerous and bacterial resistant medicines from illegal and informal sources is important to consider the manners of drug availability to consumers [18].

As per studies in Ethiopia, the magnitude of selfmedication varied from $12.8 \%$ to $77.1 \%$, with an average of $36.8 \%$. The type of illness that leads to self-medication, sources of information for self-medication, and drugs or category of drug products that are commonly self-administered need to be understood to design interventions $[7,19]$. Some recent studies also revealed that antibiotics can be easily purchased without prescription and are accessible from kiosks (small local shops in Ethiopia). In addition, self-medication is still used more often for self-limiting illnesses and antibiotics are usually used by consumers. All these scientific findings have shown that antibiotics are not only highly consumed but also irrationally used. They also indicate that Ethiopia still faces some challenges related to regulatory enforcement from socioeconomic, demographic, and patient-related health facilities and policy related concerns $[2,7,19,20]$.

A study conducted in Butajira (Southern Ethiopia) indicated that $15 \%$ of people with perceived illnesses performed self-medication [21]. In another study conducted in Addis Ababa and Central Ethiopia, the magnitude of self-care was as high as $50 \%$. Low severity/pain of illness or diseases and poverty were the major reasons for self-medication [2].

In previous studies, the association between being a CBHI member and the self-medication trend has not been studied yet in Ethiopia. Therefore, this study aimed to assess the prevalence and the nature of these practices in the $\mathrm{CBHI}$ members and nonmembers levels, which is important to devise appropriate educational, regulatory, and administrative measures.

\section{Methods and Materials}

2.1. Study Setting. A community based comparative crosssectional study was conducted in a community in Limmu Genet town from February to March 2016, because in the town there are a number of private pharmacies and governmental hospitals which provide both preventive and curative services for communities in and out of the catchment areas. Limmu Genet is located $425 \mathrm{kms}$ and $75 \mathrm{kms}$ southwest of Addis Ababa, the capital of Ethiopia, and Jimma, the capital of Jimma Zone, respectively. It has a total surface area of 1200 hectares. It is bounded by Sokoru in the east, Gomma in the west, Limmu Sakka in the north, and Kersa in the south. The total projected population of the town from the 2007 Central Statistical Agency (CSA) census report is 12,674. The town has a temperature within the range of $30^{\circ} \mathrm{C}$ and an average annual 
rainfall of $800-2500 \mathrm{~mm}^{3}$ and is at an altitude of $1750-2000 \mathrm{~m}$ above sea level.

2.2. Participants, Sample Size, and Sampling Techniques. All households found in Limmu Genet town during the study period were used as the source population of the study. The study population was selected from community health insurance members and nonmembers, found in Limmu Genet town during the study period, who were regarded as the source population of the study. Based on eligibility criteria of households, members and nonmembers of CBHI were the study units. All community health insurance members and nonmembers were included in the study. All community health insurance members aged below 18 years were excluded. After this, 422 study participants were recruited in the study.

The multistage systematic sampling technique was used to select participants for data collection from the community. After the sample size was determined, the systematic random sampling technique was applied. Systematic random sampling was used to select study participants.

2.3. Data Collection Procedure and Instruments. Data collection tools were adapted from various literatures after a thorough revision of them. The questions and statements were grouped and arranged according to the particular objectives that they could address. The instruments included both closed-ended and open-ended questionnaires.

Data was collected on self-medication for both the health insurance members and the nonmembers. One questionnaire took an average of 20-30 minutes for a person. Patient characteristics such as sociodemographics and history of drug use were recorded.

2.4. Data Analysis. Data were analyzed using SPSS version 20. Descriptive statistics were used to illustrate proportions, tables, and means. Rates of total self-medication were calculated for each of the variables considered. Statistical analysis was carried out using Pearson's CBHI square with values of $P<0.05$ taken as significant.

To estimate the independent effect of each of these variables on self-medication, further statistical analysis was carried out by linear regression. Initially, data showed that being a member of community insurance was found to be an important factor in self-medication and, in turn, community insurance might have influenced other variables.

2.5. Quality Control. There was regular cross-checking for the completeness of the questionnaires. The data collection tool was pretested for its validity. The data collection tool was first prepared in English and later translated to Afan Oromo local language to keep meaning consistency. To avoid information bias, pretest was conducted in the adjacent district town, and after getting feedback from the pretest we revised the tool to maintain validity.

2.6. Ethical Clearance. The ethical approval and clearance letter of permission was obtained from Jimma University; an official letter was obtained from the Department of Pharmacy.
During data collection, all respondents were asked for their permission and informed consent was obtained prior to the interview. An official letter was sent to Limmu Genet's health center and hospital. The confidentiality of the study participants was secured.

\section{Results}

3.1. Sociodemographic Characteristics of the Respondents. This population-based survey examined three hundred and eighty-nine households which were sampled from three kebeles. Of the total 422 questionnaires distributed to be filled by respondents, 389 were filled completely and collected, which gave a response rate of $92.2 \%$. The mean age of the respondents was 42.2 years $(\mathrm{SD}=13.7)$. The minimum age was 18 and the maximum was 90 . Since the interview was conducted with female household heads, $47.6 \%$ of the respondents were females. Regarding the respondents' family monthly income, the majority, $37.0 \%$, reported a monthly income of between 1001 and 1500 Ethiopian Birr (Table 1).

3.2. Characteristics of the Sick Person. From a total of 389 households, three hundred and eight (308) household members had faced health-related problems within the last two weeks prior to the study, translating to an illness prevalence of $91.8 \%$. But the degree of illness varies from person to person. Among them, 241 (78.2\%) treated themselves. No households reported more than one ill person. About $95.4 \%$ of the sick individuals were married. Females, $48 \%$, reported less illness than males, $52 \%$.

3.3. Perceived Illness Treated with Self-Medication with Drugs. Depending on the different socioeconomic and sociodemographic factors, the types, extents, and reasons for selfmedication can vary from country to country. In this study, self-medicated participants were 237 with health problems out of 304 with illness conditions. This made self-medication's prevalence $78.1 \%$. Over $70 \%$ of CBHI members and $30 \%$ of nonmembers practiced self-medication. The most common types of ailments for which the respondents reported practicing self-medication were cough and fever (Table 3 ).

3.4. Extent and Reason for Self-Medication with Drugs. The major reasons listed by the self-medicated study participants are shown in Table 2. Concerning reasons of self-medication respondents, about $114(67 \%)$ and $63(70 \%)$ of CBHI members and nonmembers, had low cost alternatives in money and time, respectively. But only 6 (3\%) of CBHI members had prior experience to the illness and/or the self-drug intake. About 56 (26\%) and 21 (23\%) CBHI members and nonmembers believed that self-medication is an emergency care, respectively.

3.5. Major Drug Classes Used for Self-Medication. Out of 241 self-medicated participants, the most commonly requested categories of drugs were analgesics/antipyretics (93, $38.5 \%)$, antimicrobials (91,36.8\%), antimalarials $(28,11.8 \%)$, 
TABLE 1: Sociodemographic characteristics of respondents (head of the household), Limmu Genet town, May $2016(N=389)$.

\begin{tabular}{|c|c|}
\hline Sociodemographic profile & $N(\%)$ \\
\hline \multicolumn{2}{|l|}{ CBI } \\
\hline Members & $269(69 \%)$ \\
\hline Nonmembers & $120(31 \%)$ \\
\hline \multicolumn{2}{|l|}{ Sex } \\
\hline Male & $204(52 \%)$ \\
\hline Female & $185(48 \%)$ \\
\hline \multicolumn{2}{|l|}{ Age } \\
\hline$<18$ & $9(2 \%)$ \\
\hline $19-35$ & $133(34 \%)$ \\
\hline $36-59$ & $187(48 \%)$ \\
\hline$>60$ & $60(16 \%)$ \\
\hline \multicolumn{2}{|l|}{ Marital status } \\
\hline Married & $357(92 \%)$ \\
\hline Single & $18(5 \%)$ \\
\hline Widowed & $5(1 \%)$ \\
\hline Divorced & $9(2 \%)$ \\
\hline \multicolumn{2}{|l|}{ Religion } \\
\hline Orthodox & $121(31 \%)$ \\
\hline Muslim & $265(68)$ \\
\hline Protestant & $3(1 \%)$ \\
\hline \multicolumn{2}{|l|}{ Educational status } \\
\hline Illiterate & $139(36 \%)$ \\
\hline Grade 1-8 & $197(51 \%)$ \\
\hline Grade 9-12 & $43(11 \%)$ \\
\hline Higher education & $10(3 \%)$ \\
\hline \multicolumn{2}{|l|}{ Ethnicity } \\
\hline Oromo & $310(80 \%)$ \\
\hline Amhara & $54(14)$ \\
\hline Tigre & $7(2 \%)$ \\
\hline Other & $18(5 \%)$ \\
\hline \multicolumn{2}{|l|}{ Monthly income } \\
\hline$<550$ & $47(12 \%)$ \\
\hline $501-1000$ & $63(16 \%)$ \\
\hline $1001-1500$ & $144(37.0 \%)$ \\
\hline $1501-2000$ & $120(31 \%)$ \\
\hline$>2000$ & $15(4 \%)$ \\
\hline
\end{tabular}

anthelmintics $(28,11.8 \%)$, and traditional medicine $(3,1.0 \%)$ (Figure 1).

3.6. Sources of Information for the Practice of Self-Medication with Drugs. The two most usual sources of advice/information for self-medication were drug retail outlets (37.8\%) and healthcare providers such as doctors, nurses, and health assistants, but without formal prescriptions (42.1\%). Nevertheless, friends, neighbors, or relatives $(2 \%)$ and $37.8 \%$ of the respondents obtained information by reading drug-related materials such as labels, leaflets, or promotional materials, while $18.0 \%$ of them reported obtaining such information by previous experience (Table 4).
TABLE 2: Sociodemographic characteristics of those who reported an illness within the 2-week recall period, Limmu Genet town, May $2016(N=241)$.

\begin{tabular}{lc}
\hline Sociodemographic profile & $N(\%)$ \\
\hline CBI & $308(77 \%)$ \\
Members & $90(23 \%)$ \\
Nonmembers & \\
Sex & $157(52 \%)$ \\
Male & $147(48 \%)$ \\
Female & \\
Age & $5(2 \%)$ \\
$<18$ & $98(32 \%)$ \\
19-35 & $158(52 \%)$ \\
$36-59$ & $43(14 \%)$ \\
$>60$ & \\
Marital status & $290(96 \%)$ \\
Married & $7(2 \%)$ \\
Single & $4(1 \%)$ \\
Widowed & $3(1 \%)$ \\
Divorced & \\
Educational status & $115(38 \%)$ \\
Illiterate & $197(54 \%)$ \\
Grade 1-8 & $21(5 \%)$ \\
Grade 9-12 & $4(1 \%)$ \\
Higher education & \\
Monthly income & \\
<550 & $23(78 \%)$ \\
1001-15000 & $30(10 \%)$ \\
1501-2000 & $129(42 \%)$ \\
\hline & $114(38 \%)$ \\
\hline & $8(3 \%)$ \\
\hline
\end{tabular}

3.7. Determinants of Self-Medication with Drugs. As shown in Tables 5 and 6, the result of crosstabs analysis revealed that, in some variables, significant associations were observed on the practice of SMA and community health insurance members and nonmembers.

\section{Discussion}

Self-medication in our study was much higher than it was in previous studies. Mainly, the increasing healthcare cost and the shift in the pattern of diseases towards chronic ones (from $30 \%$ to $80 \%$ in 40 years) led to a more person-centric approach involving self-care and responsible self-medication $[6,22]$. Recent reports from developed countries clearly show extensive use of self-medication. Worldwide studies also showed a range of self-medication practices between $15 \%$ and $80 \%[1,23]$.

In this study, the prevalence of self-medication was found to be $78.2 \%$, which is almost more or less similar to other studies in the country $[1,23]$. However, this result was higher than the results of some other studies done in Ethiopia $[7,18,20,24]$. It is more than three times higher than the 
TABLE 3: Type of illness reported $(N=241)$ and action taken by the study participants, May 2016, Limmu Genet town.

\begin{tabular}{lccr}
\hline Type of illness & $\begin{array}{c}\text { Community based health } \\
\text { insurance members, } N(\%)\end{array}$ & $\begin{array}{c}\text { Community based health } \\
\text { insurance nonmembers, } N(\%)\end{array}$ & Total, $N(\%)$ \\
\hline Headache & $25(68.9 \%)$ & $11(31.1 \%)$ & $36(14.8 \%)$ \\
Fever & $35(66.7 \%)$ & $17(33.3)$ & $52(21.7 \%)$ \\
Cough & $38(70.6 \%)$ & $16(29.4)$ & $54(22.4 \%)$ \\
Diarrhea & $37(73.0 \%)$ & $14(27.0)$ & $51(20.7 \%)$ \\
Others & $34(72.9 \%)$ & $14(27.1 \%)$ & $48(19.4 \%)$ \\
\hline Total & $170(70.4 \%)$ & $71(29.6 \%)$ & $241(100 \%)$ \\
\hline
\end{tabular}

TABLE 4: Reasons for self-medication in community in Limmu Genet town $(N=241)$, May 2016.

\begin{tabular}{|c|c|c|c|c|c|}
\hline \multirow[b]{2}{*}{$\begin{array}{l}\text { Community based } \\
\text { health insurance }\end{array}$} & \multicolumn{4}{|c|}{ Reason for self-medication } & \multirow[b]{2}{*}{ Total } \\
\hline & $\begin{array}{c}\text { Low cost } \\
\text { alternative in } \\
\text { money and time }\end{array}$ & $\begin{array}{l}\text { Illness was minor } \\
\text { (not serious) }\end{array}$ & Emergency & $\begin{array}{c}\text { Previous } \\
\text { experience of drug } \\
\text { use }\end{array}$ & \\
\hline Member & $114(67.3 \%)$ & $6(3.7 \%)$ & $45(26.2 \%)$ & $5(2.8 \%)$ & $170(70.4 \%)$ \\
\hline Nonmember & $50(70 \%)$ & $5(6.7 \%)$ & $16(23.3 \%)$ & $0(0 \%)$ & $71(29.6 \%)$ \\
\hline Total & $164(68.0 \%)$ & $11(4.6 \%)$ & $61(25.4 \%)$ & $5(2.0 \%)$ & $241(100 \%)$ \\
\hline
\end{tabular}

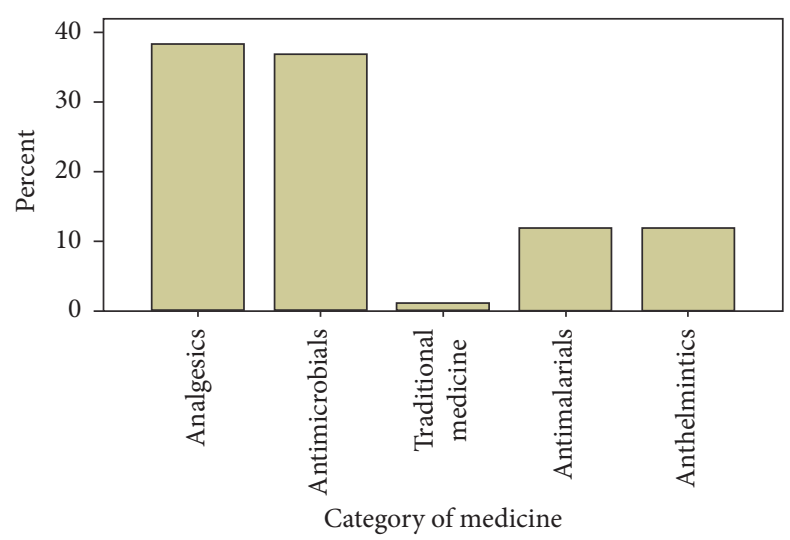

FIGURE 1: Categories of drugs requested for self-medication $(n=$ 241) in Limmu Genet community, May 2016.

findings from Spain and India. But categorically, 79.6\% of the $\mathrm{CBHI}$ members and $75 \%$ of the nonmembers practiced self-medication. Even though the practice of self-medication varies across countries, it is difficult to make any comparative analysis since there is no prior study conducted in an area similar to the one under study. Therefore, the higher proportion differences observed among different groups might be due to free access of drugs for members and charged drugs for nonmembers. In addition, nowadays, people may be aware of some drugs indications for usual and prevalent illnesses like analgesics for headache and antimalarials for malaria. Consequently, the prevalence of self-medication might be high if people are aware of those drug uses.

This study also showed that $37 \%$ of the study population used antibiotics without medical prescription. Recent reports from developed countries clearly show that SMA is commonly encountered. Our findings are in line with the study from Israel in which $37 \%$ of participants treated themselves with antimicrobial drugs. However, this proportion was too much higher than the ones in Northern Europe (3\%), Central Europe (6\%), and Southern Europe (19\%). This was lower than findings from Pakistan (69\%), China (48\%) [26], Sudan (one-month period prevalence was 74\%) [27], Yemen (60\%) (within two-week recall period) [28], and Ghana (70\%) [1]. This might be due to the socioeconomic difference between settings. Still we were not able to compare between two groups of CBHI due to unavailability of a similar study elsewhere. This might be increased with bacterial diseases prevalence such as diarrheal and abdominal discomfort, which might lead inhabitants to use antibiotics on their own without any prescription and regardless of being a $\mathrm{CBHI}$ member.

Higher period prevalence has been reported in most of the developing countries. This has been associated with several factors, particularly the lack of access to healthcare, availability of antibiotics as over-the-counter drugs, and the relatively higher prevalence of infectious diseases [1]. In this study, the two-week period prevalence of SMA is higher than in the previous recent studies done in Ethiopia (a threemonth period prevalence of $6.7 \%$ [18] and a two-month period prevalence of $4.8 \%$ [29]). This variation could be attributed to the recall period used in the studies or variation in the study areas.

Even if direct studies on the availability of antibiotics without prescription in pharmacies in Ethiopia are scarce, several studies have shown that the main source of drugs that are used for self-medication was pharmacies [18, 20, 24, 29].

The present study result also showed that $42 \%$ of the individuals who practiced SMA reported that they obtained drug-related information from other health professionals. Also, they obtained drug-related information (at least when 
TABLE 5: Sources of information or advice for self-medication at Limmu Genet community $(n=241)$, May 2016.

\begin{tabular}{|c|c|c|c|c|c|}
\hline \multirow{2}{*}{ Community based health insurance } & \multicolumn{4}{|c|}{ Source of information } & \multirow{2}{*}{ Total } \\
\hline & Drug retail outlet & Other health professionals & Previous experience & Neighbor & \\
\hline \multicolumn{6}{|l|}{ Member } \\
\hline Number & 68 & 62 & 36 & 4 & 170 \\
\hline \multicolumn{6}{|l|}{ Nonmember } \\
\hline Number & 23 & 39 & 8 & 1 & 71 \\
\hline Total & 91 & 101 & 44 & 5 & 241 \\
\hline
\end{tabular}

TABle 6: Association made between CBHI members and nonmembers to self-medication reported by selected background variables, May 2016 in Limmu Genet $(n=241)$.

\begin{tabular}{|c|c|c|c|}
\hline Variables & Self-medication & CBHI square & $P$ value \\
\hline \multicolumn{4}{|l|}{ Marital status } \\
\hline Married & $230(95.4 \%)$ & \multirow{4}{*}{$X^{2}=28.8$} & \multirow{4}{*}{$P>0.05$} \\
\hline Single & $6(2.3 \%)$ & & \\
\hline Widowed & $4(1.6 \%)$ & & \\
\hline Divorced & $1(0.98 \%)$ & & \\
\hline \multicolumn{4}{|l|}{ Educational status } \\
\hline Illiterate & $91(37.8 \%)$ & \multirow{4}{*}{$X^{2}=34.8$} & \multirow{4}{*}{$P<0.000$} \\
\hline Grade $1-8$ & $130(53.9 \%)$ & & \\
\hline Grade 9-12 & $17(6.9 \%)$ & & \\
\hline Higher education & $4(1.3 \%)$ & & \\
\hline \multicolumn{4}{|l|}{ Monthly income } \\
\hline$<550$ & $18(7.5 \%)$ & \multirow{5}{*}{$X^{2}=9.08$} & \multirow{5}{*}{$P>0.059$} \\
\hline $501-1000$ & $24(9.8 \%)$ & & \\
\hline $1001-1500$ & $102(42.4 \%)$ & & \\
\hline $1501-2000$ & $90(37.5 \%)$ & & \\
\hline$>2000$ & $6(2.6 \%)$ & & \\
\hline \multicolumn{4}{|l|}{ Occupation } \\
\hline Farmer & $121(50 \%)$ & \multirow{5}{*}{21.98} & \multirow{5}{*}{$P<0.000$} \\
\hline Merchant & $81(33.8 \%)$ & & \\
\hline Government employed & $9(2.9 \%)$ & & \\
\hline Daily laborers & $23(9.5 \%)$ & & \\
\hline Other & $9(3.6 \%)$ & & \\
\hline
\end{tabular}

to take and what should never be taken with the drug) from the dispensers. This is not in agreement with studies done in most developed countries where leftovers from previous courses and from relatives were the main sources of drugs for the practice of SMA $[25,26]$. This implies that healthcare professionals take care of information regarding the right place, route, time, dose, and frequency of medication while dealing with it.

While it was consistent with what has been reported in previous studies in Africa [1,15,27,28], a similar study in India also found that $20 \%$ of the antibiotics are purchased without a doctor's prescription [30].

Findings from key informants with private community pharmacists also showed that private pharmacies were the major source of drugs for self-medication. All of them reported that people could buy antibiotics without a prescription, and when antibiotics are requested by consumers, requests are neither refused nor questioned. Though antibiotics are prescription-only drugs, community pharmacists dispense these drugs without a doctor's prescription. This might lead to the misuse or overuse of antibiotics. This irrational use of antibiotics promotes antibiotic resistance [31]. The consequence of this is the switch from relatively cheap drugs to new drugs, which will be more expensive for developing countries such as Ethiopia. Overall, this indicates that there is a weak regulatory system in the study area. In addition, pharmacists should respect their professions.

Previous experience with similar symptoms and mildness of the illness were the two major reasons for SMA in this study. The main reasons for SMA in developing countries include OTC sale of antibiotics, high cost of medical consultation, low satisfaction with medical practitioners, and misconceptions regarding the efficacy of antibiotics [30]. The implication of prompt consideration is important regarding affordability and availability of drugs and medical supplies in public health facilities.

The present study results showed that some sociodemographic variables had a significant association with the practice of SMA. This finding is consistent with several study results in Africa and Ethiopia where the educational level is a significant factor for the practice of SMA $[18,21,30]$. Similar researches conducted in Sudan and Yemen also showed that the risk of SM was higher among females compared to males or that females had a higher risk of self-medication behavior compared to males $[27,28]$.

The prominent limitations of this study were the lack of previous comparative, cohort, or RCT studies, which made the discussion poor. Also, the recall bias might affect the prevalence and type of drug used by the participants. In addition, participants were asked simply for self-medication but not for the type of drugs they used. This might make sense for all types of drugs used by them.

\section{Conclusion}

There is no significant difference between members and nonmembers of CBHI concerning self-medication in the study area. Although appropriate self-medication can be advantageous without proper education of the public and proper regulation of potent drugs dispensary, it may cause tragic consequences. Thus, health education regarding the dangers of self-medication must also be given with impressive attention. 
Therefore, education on the prescription and use of medicines as well as strengthening the CBI scheme utilization among the society is needed. Further interventional studies are needed to evaluate the effect size of being a CBHI member versus self-medication in the study area.

\section{Abbreviations}

AMR: Antimicrobial resistance

CBHI: Community based health insurance

GC: Gregorian calendar

JU: Jimma University

LMICs: Low- and middle-income countries

RCT: Randomized controlled trial

SMA: Self-medication with an antimicrobial

WHO: World Health Organization.

\section{Data Availability}

All relevant data are within the paper and supporting information files but any additional data required by the journal can be available anytime.

\section{Conflicts of Interest}

The authors declare they have no conflicts of interest.

\section{Acknowledgments}

The authors' heartfelt gratitude goes to the College of Health Sciences and the Department of Pharmacy, Jimma University, for funding this research. Last but not least, the authors would like to thank all the study participants.

\section{References}

[1] B. Begashaw, F. Tessema, and H. A. Gesesew, "Health care seeking behavior in Southwest Ethiopia," PLoS ONE, vol. 11, no. 9, Article ID e0161014, 2016.

[2] P. C. Miller, G. Rashida, Z. Tasneem, and M. U. Haque, "The effect of traditional birth attendant training on maternal and neonatal care," International Journal of Gynecology and Obstetrics, vol. 117, no. 2, pp. 148-152, 2012.

[3] T. Andualem, "G/Mariam T. Self-medication practices in Addis Ababa," EthiopianJournal of Health Sciences, vol. 14, no. 1, p. 92, 2004.

[4] World Health Organization, "Guidelines for the Regulatory Assessment ofMedicinal Products for Use in Self-Medication," in World Health Organization, World Health Organization, 2000.

[5] Z. S. Lassi, B. A. Haider, and Z. A. Bhutta, "Community-based intervention packages for reducing maternal and neonatal morbidity and mortality and improving neonatal outcomes.," Cochrane Database of Systematic Reviews (Online), vol. 11, p. CD007754, 2010.

[6] C. J. Gill, G. Phiri-Mazala, N. G. Guerina et al., "Effect of training traditional birth attendants on neonatal mortality (Lufwanyama Neonatal Survival Project): Randomised controlled study," BMJ, vol. 342, no. 7793, article no. d346, p. 373, 2011.
[7] A. S. Nyamtema, D. P. Urassa, and J. van Roosmalen, "Maternal health interventions in resource limited countries: A systematic review of packages, impacts and factors for change," $B M C$ Pregnancy and Childbirth, vol. 11, article no. 30, 2011.

[8] S. Suleman, A. Ketsela, and Z. Mekonnen, "Assessment of self-medication practices in Assendabo town, Jimma zone, southwestern Ethiopia," Research in Social \& Administrative Pharmacy, vol. 5, no. 1, pp. 76-81, 2009.

[9] A. Abdelmoneim, E. Idris, M. Lloyd, and T. Lukman, "Selfmedication with antibiotics and antimalarials in the community of Khartoum State," Journal of Pharmacy \& Pharmaceutical Sciences, vol. 8, no. 2, pp. 326-331, 2005.

[10] O. Cars and P. Nordberg, Antibiotic resistance - The faceless threat. BMJ 337:a1438, 2008.

[11] C. Sialubanje, K. Massar, D. H. Hamer, and R. A. C. Ruiter, "Personal and environmental predictors of the intention to use maternal healthcare services in Kalomo, Zambia," Health Education Research, vol. 29, no. 6, pp. 1028-1040, 2014.

[12] D. Almasdy and A. Sherrif, "Self-Medication Practice with Nonprescription Medication among University Students: a review of the literature," Archives of Pharmacy Practice, vol. 2, no. 3, pp. 95-100, 2011.

[13] WHO, Community based Health Insurance Schemes in Developing Countries: facts, problems and perspectives, 2003.

[14] B. Criel, MP. Waelkens, and W. Soors, "Atim C . Community health insurance in developing countries," in International encyclopedia of public health, K. Heggenhougen and S. Quah, Eds., vol. 1, pp. 782-791, 2008.

[15] S. Gabrysch, S. Cousens, J. Cox, and O. M. R. Campbell, "The influence of distance and level of care on delivery place in rural Zambia: A study of linked national data in a geographic information system," PLoS Medicine, vol. 8, no. 1, Article ID e1000394, 2011.

[16] M. C. Varkevisser, I. Pathmanathan, and A. Brownlee, Designing and conducting health systems research project: proposal development and field work, KIT Publishers International Development Research Centre, Amsterdam, Netherlands, 2003.

[17] Centers for Disease Control and Prevention (CDC), Antibiotic resistance threats in the United States, 2013, http:// www.cdc.gov/drugresistance/threat-report-2013/pdf/ar-threats2013-508.

[18] B. K. Paul and D. J. Rumsey, "Utilization of health facilities and trained birth attendants for childbirth in rural Bangladesh: An empirical study," Social Science \& Medicine, vol. 54, no. 12, pp. 1755-1765, 2002.

[19] D. A. Mossa, N. T. Wabe, and M. T. Angamo, "Self-medication with antibiotics and antimalarials in the community of silte zone, South Ethiopia," TAF Preventive Medicine Bulletin, vol. 11, no. 5, pp. 529-536, 2012.

[20] S. Worku and A. G/Mariam, "Practice of Self-medication in Jimma Town," Ethiopian Journal of Health Development, vol. 17, no. 2, 2004.

[21] G. B. Gutema, D. A. Gadisa, Z. A. Kidanemariam et al., "Self-medication practices among health sciences students: the case of Mekelle University," Journal of Applied Pharmaceutical Science, vol. 1, no. 10, pp. 183-189, 2011.

[22] Y. Kawakatsu, T. Sugishita, K. Oruenjo et al., "Determinants of health facility utilization for childbirth in rural western Kenya: Cross-sectional study," BMC Pregnancy and Childbirth, vol. 14, no. 1 , article no. 265, 2014. 
[23] K. Allendorf, "The Quality of Family Relationships and Use of Maternal Health-care Services in India," Studies in Family Planning, vol. 41, no. 4, pp. 263-276, 2010.

[24] C. Grigg, S. K. Tracy, R. Daellenbach, M. Kensington, and V. Schmied, "An exploration of influences on women's birthplace decision-making in New Zealand: A mixed methods prospective cohort within the Evaluating Maternity Units study," $B M C$ Pregnancy and Childbirth, vol. 14, no. 1, article no. 210, 2014.

[25] S. Worku and A. G/Mariam, "Practice of self-medication in Jimma town," Ethiopian Journal of Health Development, vol. 17, no. 2, pp. 111-116, 2003.

[26] C. A. Moyer, P. Dako-Gyeke, and R. M. Adanu, "Facility-based delivery and maternal and early neonatal mortality in subSaharan Africa: a regional review of the literature.," African Journal of Reproductive Health, vol. 17, no. 3, pp. 30-43, 2013.

[27] C. R. Titaley, C. L. Hunter, M. J. Dibley, and P. Heywood, "Why do some women still prefer traditional birth attendants and home delivery?: A qualitative study on delivery care services in West Java Province, Indonesia," BMC Pregnancy and Childbirth, vol. 10, article no. 43, 2010.

[28] C. Sialubanje, K. Massar, E. M. Kirch, M. S. G. Van Der Pijl, D. H. Hamer, and R. A. C. Ruiter, "Husbands' experiences and perceptions regarding the use of maternity waiting homes in rural Zambia," International Journal of Gynecology and Obstetrics, vol. 133, no. 1, pp. 108-111, 2016.

[29] C. Wilunda, G. Quaglio, G. Putoto et al., "A qualitative study on barriers to utilisation of institutional delivery services in Moroto and Napak districts, Uganda: Implications for programming," BMC Pregnancy and Childbirth, vol. 14, no. 1, article no. 259, 2014.

[30] S. M. Abay and W. Amelo, "Assessment of self-medication practices among medical, pharmacy, and health science students in Gondar University, Ethiopia," Journal of Young Pharmacists, vol. 2, no. 3, pp. 306-310, 2010.

[31] A. De Jonge, J. A. J. M. Mesman, J. Manniën, J. J. Zwart, J. Van Dillen, and J. Van Roosmalen, "Severe adverse maternal outcomes among low risk women with planned home versus hospital births in the Netherlands: Nationwide cohort study," BMJ, vol. 346, no. 7914, Article ID f3263, 2013. 

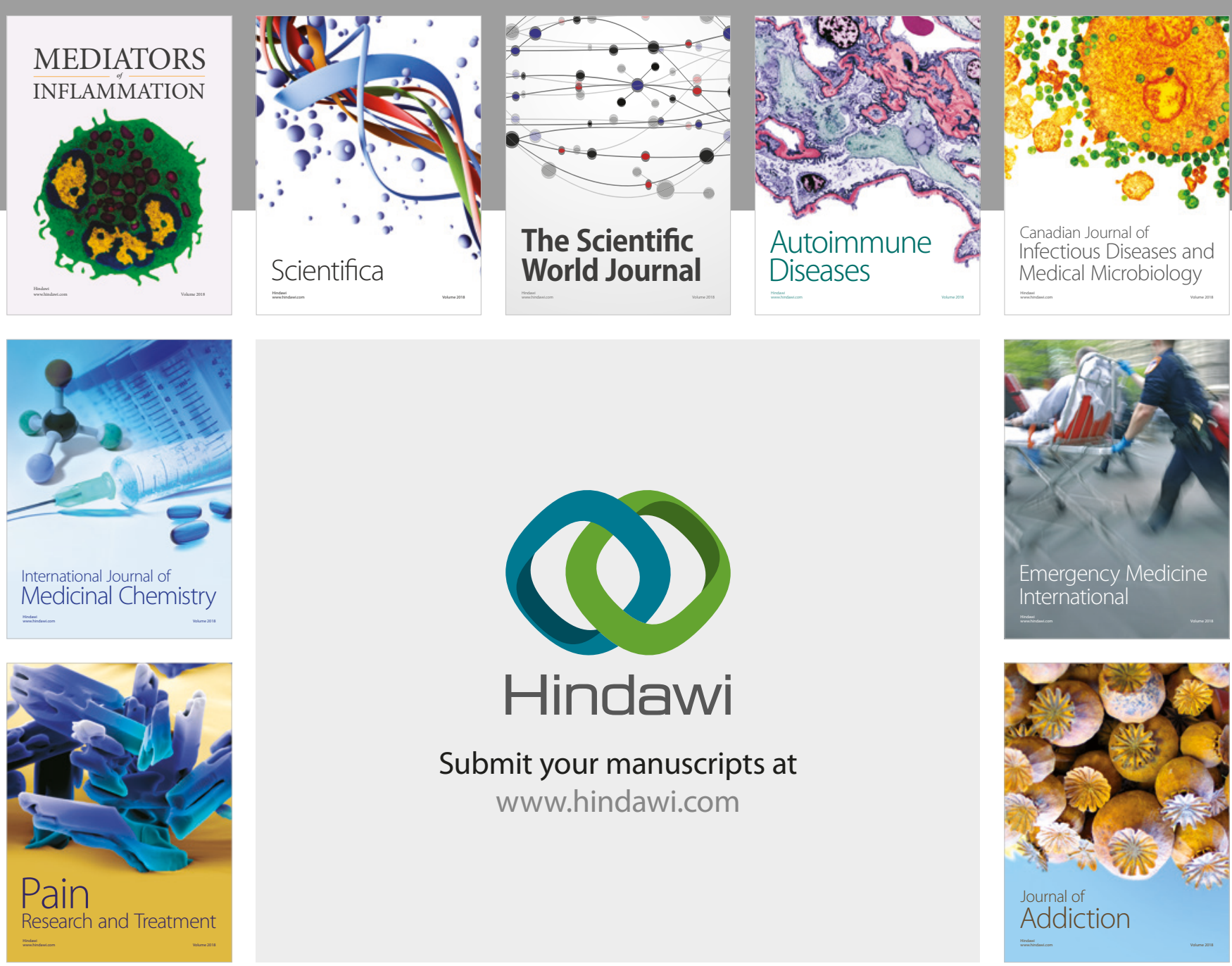

Canadian Journal of
Infectious Diseases and Medical Microbiology

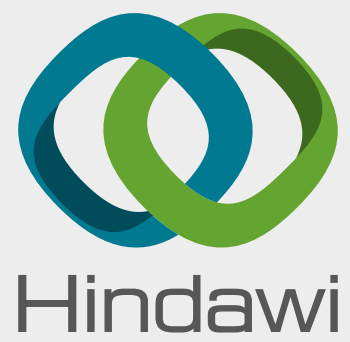

Submit your manuscripts at

www.hindawi.com
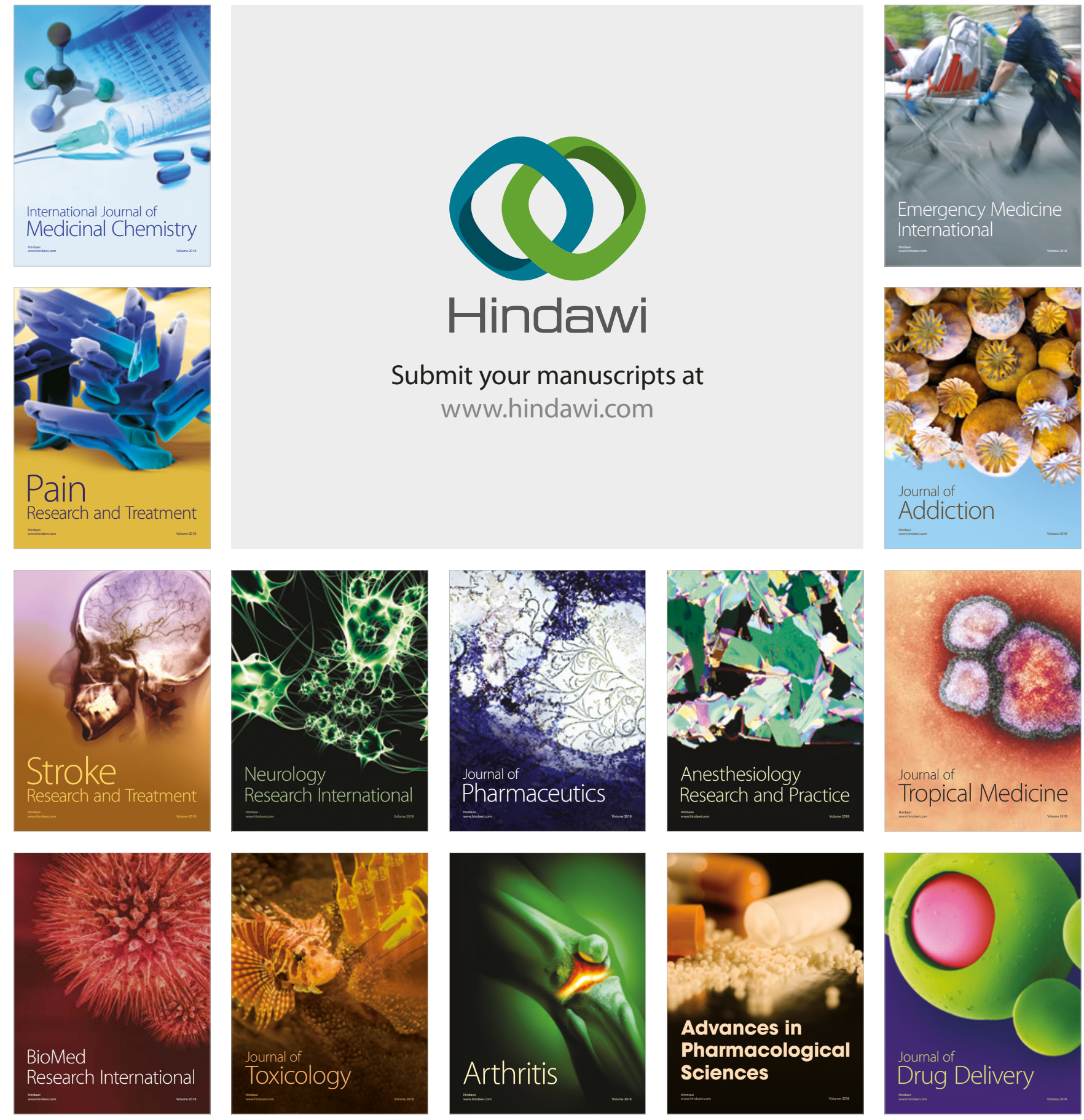